\title{
BRECHT E ARISTÓTELES
}

\author{
Mário Fernando BOLOGNESI ${ }^{1}$
}

- RESUMO: A concepção teatral de Brecht não é radicalmente oposta à de Aristóteles. A estética brechtiana, em muitos aspectos, é herdeira das idéias de Aristóteles. O teatro épico proposto por Brecht tem em seu horizonte de combate o teatro de matriz naturalista e o drama psicológico. Mimese e catarse não significam identificação do público com a cena e com o herói.

- PALAVRAS-CHAVE: Teatro épico; Teatro dramático; Aristóteles; Brecht.

\section{1}

Quando se faz alusão às teorias do teatro, Brecht e Aristóteles são comumente postos em campos contrários. Isso decorre, sem dúvida, da distinção proposta pelo próprio Brecht entre o teatro dramático e o épico, sendo o dramático identificado, nesse caso, com o aristotélico. A polaridade central do teatro épico não se dá com Aristóteles e a tragédia, mas sim com o naturalismo e seu drama psicológico e com o romantismo tardio, matrizes majoritárias do fazer teatral nos tempos de Brecht. As implicações desta demonstração, de imediato, apontam para uma revisão das teorizações de Aristóteles que conduz à seguinte constatação: recuperar Aristóteles significa ir ao encontro do primeiro teórico que apre-

1 Departamento de Filosofia, Faculdade de Filosofia e Ciências, UNESP/Marília. 
senta a arte como um fazer, como produção, como trabalho, enfim, como possibilidade de conhecimento. Esta concepção está próxima à de Brecht. Assim, qualquer tentativa de estabelecer uma filiação teórica para o teatro épico deveria levar em conta os seguintes autores: Aristóteles-Marx-Brecht. O autor intermediário desta equação será deixado de lado, mesmo porque as ligações de Brecht com o marxismo são amplamente reconhecidas. Do vasto cabedal de assuntos a que a ligação com Aristóteles induz, convém voltar às idéias de mimese e de catarse, centrais na Poética, e que foram retomadas pelo autor de Mãe coragem. Antes, no entanto, faz-se necessário um apanhado geral acerca dos tópicos essenciais da filosofia aristotélica.

Aristóteles divide as ciências e as formas de conhecimento em três classes: $1^{\circ}$ ) ciências teoréticas; $2^{\circ}$ ) ciências práticas; $3^{\circ}$ ) ciências poéticas. As primeiras têm por objeto o saber e a verdade e se materializam na matemática, na física e na metafísica. As segundas estudam as ações elas mesmas e se ligam à práxis. Destas, participam a ética, a política e a economia. As poéticas têm por objeto a produção de uma obra, a criação de algo, ou seja, a realização da passagem do ser em potência ao ser em ato, fazendo confluir a matéria e a forma. As teoréticas teriam a lógica como instrumento de trabalho, por intermédio da indução e do silogismo; as ciências práticas fundam-se na virtude e as poéticas, no fazer. Todas, entretanto, fazem uso do reto raciocínio. Há, evidentemente, uma hierarquização entre as diversas ciências, correspondentes a formas específicas de se alcançar a verdade. ${ }^{2}$

O conhecimento científico tem como ponto de partida a experiência e a indução. Entretanto, o procedimento indutivo não é suficiente para se alcançar os universais (todo conhecimento científico é conhecimento do universal). À indução associa-se o silogismo, e este procede justamente dos conteúdos universais. O silogismo opera por raciocínio dedutivo, a partir dos dados oferecidos pela experiência e pela indução. Ele é neces-

\footnotetext{
2 De acordo com Aristóteles, são elas: "a arte, o conhecimento científico, a sabedoria prática, a sabedoria filosófica e a razão intuitiva (não incluímos o juízo e a opinião porque estes podem enganar-se)" (Ética a Nicômaco, VII, 3, 1139b, p.15 ss.).
} 
sário porque é característica do conhecimento científico a demonstração do conhecido, por recursos da razão.

A razão intuitiva diz respeito à apreensão dos primeiros princípios e das primeiras causas, dos quais decorrem todas as formas de conhecimento e todas as ciências. A sabedoria filosófica é justamente a combinação da razão intuitiva com o conhecimento científico e se firma, para Aristóteles, na mais perfeita forma de conhecimento, a metafísica, a ciência do Ser, aquela que sustenta todas as demais formas do conhecer.

O conhecimento científico é demonstrativo, mas supõe um conhecimento não demonstrável: os primeiros princípios e as primeiras causas, objetos da metafísica. A ciência do Ser investiga o que há de mais geral e comum a todas as coisas, ou seja, os atributos essenciais do Ser: o Uno e o Múltiplo, o Mesmo e o Outro, os contrários etc. Por exemplo, a matemática trabalha com a idéia de grandeza; a física, com a de movimento. Para a primeira, o ser é traduzível em quantidade; para a outra, a física, o ser se expressa no movimento. A filosofia engloba-as e se interessa em saber que a quantidade e o movimento são, ambos, atributos do Ser.

Mas o Ser tem diversos sentidos. Eles se efetivam em uma ordem física e, para tal, Aristóteles formula as distinções entre matéria e forma, ser em potência e ser em ato. Todo particular é composto de matéria e forma. Uma estátua, por exemplo, tem como matéria o bronze; como forma, a figura enquanto tal. O seu todo é o conjunto de matéria e forma.

Os sentidos do Ser dão-se também em uma ordem lógica. Segundo esta o Ser se prende a sentidos diversos, segundo as categorias. A metafísica, enquanto filosofia primeira, move-se exclusivamente pelo princípio de identidade e de não contradição, espécie de lei suprema do pensamento, segundo a qual é impossível ser e não ser ao mesmo tempo. Assim, não se pode dizer que uma coisa é e não é. Não se pode, concomitantemente, negar e afirmar. Não se pode dizer que um mesmo atributo pertence e não pertence a um mesmo sujeito, ao mesmo tempo e sob o mesmo aspecto. Enfim, não pode haver termo médio entre o negar e o afirmar. A substância ou essência de cada coisa é própria e comum a ela e não a outras. $\mathrm{O}$ universal não é essência das coisas particulares, mas comum a todas. Assim, cabe à metafísica estudar o que há de comum a uma série de substâncias, com vistas à classificação em um gênero, determinando as diferenças.

A sabedoria prática, por seu lado, envolve a virtude e a capacidade humana de tomar decisões sábias e corretas para os homens, visando ao bem coletivo. Rege-se, portanto, pelo princípio da práxis, da ação propri- 
amente dita, e diz respeito às decisões políticas, à legislação, às normas e aos hábitos, para uma adequada postura ética e moral. ${ }^{3}$ Toda boa ação ou deliberação necessita da intervenção do reto raciocínio. ${ }^{4}$

O saber prático difere da ciência e de sua forma de conhecimento pelo critério da necessidade. O conhecimento científico envolve demonstração e esta só é possível a partir de princípios primeiros, invariáveis, regentes últimos de todas as ciências. Não se pode deliberar sobre o necessário. Ele se impõe como tal. A deliberação é justamente o ato de escolha entre possibilidades várias e distintas. (Ética a Nicômaco, VI, 5. 1140b, p.1-5) Ele também não é uma arte porque esta é produção, e não ação. As ciências práticas fundam-se na noção de práxis e as poéticas, na poiêsis. Ambas diferem quanto à finalidade. Na práxis, o fim está na ação ela mesma; a produção tem o seu fim em algo externo. ${ }^{5}$

O produzir envolve um projetar anterior, uma idéia e uma orientação raciocinada, tendo em vista a matéria (ou as matérias) com a(s) qual(is) se trabalhará e o domínio técnico de transformação da matéria. Em suma, as ciências poéticas efetivam a passagem do ser em potência para o ser em ato, alcançando, enfim, uma forma final. Este processo envolve a produção de algo que antes não existia. ${ }^{6}$ De acordo com Aristóteles, na Ética a Nicômaco, "a arte é uma disposição que se ocupa de produzir, envolvendo o reto raciocínio; e a carência de arte, pelo contrário, é tal disposição acompanhada de falso raciocínio" (1140a 20 ss.).

A produção de coisas pode-se dar por três espécies: a natural, relativa à natureza; a artificial, da arte; e a espontânea, atributo do acaso. ${ }^{7} \mathrm{~A}$ natureza e a arte têm em comum uma determinada finalidade. A primeira

3 Ressalte-se o sentido explícito da práxis enquanto ação que envolve a ética e a política, pois será de extrema importância para a compreensão do sentido da mimese, na tragédia.

4 "A sabedoria prática deve, pois, ser uma capacidade verdadeira e raciocinada de agir com respeito aos bens humanos" (Ética a Nicômaco, VI, 5, 1140b 20 ss.).

$5 \mathrm{Na}$ poiêsis, "um agente é requisitado para desencadear um processo cujo desfecho é natural ou não-natural" (Besnier, 1996, p.129).

6 “o resultado da produção seria um objeto 'exterior' simultaneamente ao agente que o produz e ao movimento (a poiêsis propriamente dita) pelo qual ele foi produzido, enquanto, para a ação, é o movimento mesmo, a conduta do agente, que é não apenas o fim, mas também a obra, o resultado" (Besnier, 1996, p.134). Esta é a interpretação vigente encontrada, por exemplo, em Moreau, que Besnier, no artigo citado, em parte, contestará. Como não se trata, aqui, de investigar a fundo tal problemática registre-se, ao menos, a sua pertinência.

7 "Efetivamente, os seres são gerados quer por arte, quer por natureza, ou por acaso, ou ainda espontaneamente. Ora, a arte é um princípio de movimento que reside em outro ser, a natureza é um princípio no próprio ser (pois o homem gera o homem), e as outras causas são privações destas duas" (Metafisica, XII, 3, 1070a 4-9). Como exemplo de produção espontânea pode ser considerada a cura, ou seja, o restabelecimento da natureza, sem o concurso da arte. Este tipo de produção refere-se a tudo que não advém de uma situação premeditada. 
tem o fim em si mesma, portanto, intrínseco; a segunda, tem uma finalidade exterior, na transformação, no movimento, enfim, na geração de coisas. A produção é adaptação dos meios disponíveis aos fins almejados. A adaptação biológica não é resultado de arranjos acidentais. Na natureza, o acidental é exceção. A adaptação biológica é constante. A finalidade é perceptível em um processo orientado, numa série de movimentos dirigidos para um determinado fim. ${ }^{8} \mathrm{Na}$ natureza, como na arte, há adaptação dos meios aos fins.

A finalidade do trabalho produtivo, para Aristóteles, é imitação do finalismo da natureza. A diferença consistiria em que a arte é um princípio de organização exterior, que age sobre uma outra coisa; a natureza, um princípio imanente, cuja ação se dá no próprio sujeito (Metafísica, XII, 1070a 7-8). Se o fazer artístico fosse imanente às obras, ou seja, dadas em si mesmas; se a arte da construção naval fosse imanente às árvores, ela agiria como a natureza, sem o ato de deliberar, portanto, de um modo tipicamente teleológico (Física, II, 8, 199b 28-29).

Este princípio de organização exterior (consciência externa) tem como atributo o ato de deliberar. A natureza age de um modo teleológico e imanente, portadora de um princípio organizador intrínseco. A arte prevê um agente externo, um "projeto" anteriormente concebido e a execução que ele demanda. A arte produz aquilo que a natureza é incapaz de gerar, ou, no limite, a produção artificial imita a natureza (Física, II, 8, 199a 15-19). ${ }^{9}$

Uma vez expostas as bases filosóficas mais gerais do pensamento de Aristóteles cabe, na continuidade, verificar como essas temáticas são abordadas na Poética. Antes, vale lembrar que as ciências poéticas, na concepção aristotélica, referem-se a todo e qualquer trabalho produtivo, envolvendo desde a composição de tragédias, comédias e epopéias,

\footnotetext{
8 "A conservação da forma, o perpetuar da espécie, eis, em vez da perenidade do indivíduo, o fim da geração e da vida" (Moreau, 1962, p.111).

9 "É isto que permite a Aristóteles dizer que a arte imita a natureza: ela utiliza os procedimentos já desenvolvidos pela natureza" (Moreau, 1962, p.112).
} 
como também a agricultura, a tecelagem e todas as outras formas de produção e fabricação de bens e coisas, como as artesanais. ${ }^{10}$

A postura "experimental" de Aristóteles, de valorização das coisas e dos fenômenos sensíveis, levou-o a escrever (em torno de 334 e 330 a. C.) uma teoria particular do teatro e da literatura, que ficou conhecida como Poética. Ele elaborou os conceitos de mimese e o de catarse a partir do exame da tragédia e da comédia gregas. O sentido desse imitar pode ser precisado tanto em termos intrínsecos, isto é, relativo à própria atividade do poeta, quanto em termos gerais, no interior do complexo das sabedorias poéticas, tal como exposto anteriormente.

Referindo-se à tragédia, diz Aristóteles:

É pois a tragédia imitação de uma ação de caráter elevado, completa e de certa extensão, em linguagem ornamentada e com as várias espécies de ornamentos distribuídas pelas diversas partes [do drama], [imitação que se efetua] não por narrativa, mas mediante atores, e que, suscitando o "terror e a piedade, tem por efeito a purificação dessas emoções”. (Poética, VI, 1449b 24-27)

A tragédia não é imitação de uma ação qualquer; ela é imitação de uma práxis. No sentido aristotélico, práxis refere-se ao saber prático e diz respeito a atos éticos e políticos. É uma ação que visa à vida coletiva, à tomada de decisões para o bem da cidade. É a escolha do governante diante de diversas possibilidades, tendo como pressuposto a cidade e os cidadãos. Vê-se, assim, um certo objetivo e uma finalidade para a tragédia, aliando-a à ética e à política. A tragédia, então, enquanto produção poética, tem como motivo de imitação não a natureza em si mesma (o que seria um contra-senso, pois ela se volta para a cena, para a representação), mas as ações (práxis) humanas.

A tragédia é uma arte mimética. Ela apresenta-se como um todo organizado. Comporta, por exemplo, um fim, qual seja, a catarse ("imitação de uma ação de caráter elevado, completa e de certa extensão ... e que suscitando o "terror e a piedade, tem por efeito a purificação dessas emoções..."”) e um meio ("em linguagem ornamentada e com as várias espé-

\footnotetext{
10 A distinção entre o artesanato, que buscava a união do útil ao belo, e as artes, que almejavam a satisfação da alma, só vai se dar durante o Império Romano, a partir de uma distinção socioeconômica bastante clara. "As artes liberales eram exercidas por homens livres; já os ofícios, artes serviles, relegavam-se a gente de condição humilde. E os termos artista e artifice (de artifex: o que $f a z$ a arte) mantêm hoje a milenar oposição de classe entre o trabalho intelectual e o trabalho manual" (Bosi, 1985, p.14).
} 
cies de ornamentos distribuídas pelas diversas partes [do drama], [imitação que se efetua] não por narrativa, mas mediante atores."). ${ }^{11}$

A tragédia é imitação de ações. Os homens têm qualidades de acordo com o caráter e são bem ou mal-aventurados pelas ações praticadas. "Daqui se segue que, na tragédia, não agem as personagens para imitar caracteres, mas assumem caracteres para efetuar certas ações; por isso as ações e o mito constituem a finalidade da tragédia, e a finalidade é de tudo o que mais importa" (ibidem, 1450a 20-22).

O mito é o elemento primordial da tragédia e a imitação do caráter dos agentes o seu complemento ideal e necessário. Ambos se completam com o pensamento, com a elocução, isto é, o enunciado dos pensamentos, a melopéia, e o modo como as palavras são pronunciadas, e, por fim, o espetáculo cênico, segundo Aristóteles, o mais emocionante e o menos artístico dos elementos (ibidem, 1450a 16-21).

A tragédia é expressão de visões contraditórias sobre o mundo, uma problematização dos dilemas vividos por Atenas na época democrática. Mito e pensamento; valores mercantis e aristocráticos; interesses humanos e necessidades políticas; deuses e homens; vontade coletiva e desejo individual - todo esse universo conflitante está presente na composição trágica. Nos dizeres de Vernant e Vidal-Naquet (1977, p.27), “Tensão entre o mito e as formas de pensamento próprias da cidade, conflitos no homem, o mundo dos valores, o universo dos deuses, caráter ambíguo e equívoco da língua - todos esses traços marcam profundamente a tragédia grega".

Os conflitos constituintes da tragédia são correlatos àqueles do século $\mathrm{V}$ ateniense e sua experiência democrática. $\mathrm{O}$ próprio espaço cênico no qual se desenvolveu a tragédia é uma abstração das instâncias políticas da democracia. O coro ocupa o lugar central circular, a orques-

11 "Já ficou assente que a tragédia é imitação de uma ação completa, constituindo um todo que tem certa grandeza, porque pode haver um todo que não tenha grandeza. 'Todo' é aquilo que tem princípio, meio e fim. 'Princípio' é o que não contém em si mesmo o que quer que siga necessariamente outra coisa, e que, pelo contrário, tem depois de si algo com que está ou estará necessariamente unido. 'Fim', ao invés, é o que naturalmente sucede a outra coisa, por necessidade ou porque assim acontece na maioria dos casos, e que, depois de si, nada tem. 'Meio' é o que está depois de alguma coisa e tem outra depois de si" (Poética, VII, 1450b 24-31). 
tra, abstração da praça pública, a Ágora. O espaço da cena é destinado às personagens objeto da tragédia, como os reis e governantes em seus palácios. Assim, a compreensão do fenômeno trágico alia-se ao entendimento do período grego da democracia, de modo que a tragédia passa a ser uma forma do real, uma abstração que hoje se dá a nós como matéria artística.

Este é o sentido preciso da mimese trágica: trazer à cena uma práxis (ação ética e política), através da exposição problematizada dos vários elementos conflituosos que permeiam a forma trágica ateniense. Com isso, e a partir disso, na sua composição trabalhada, ela almeja alcançar a catarse, ou seja, a expulsão dos sentimentos de piedade e terror, para que prevaleça o senso de razão no desfecho final. A forma trágica não deseja que os gregos alimentem piedade ou terror por Édipo: prefere que o exemplo de Édipo seja debatido e perseguido, que o ideal do bem prevaleça sobre interesses pessoais e o homem político se entregue à própria investigação.

Aristóteles percebeu a tragédia como componente da democracia. Viu nela a ética em discussão, assim como a legitimidade do ato político de governar. A tragédia é a democracia posta em evidência e devidamente problematizada, uma maneira de compreensão de Atenas e da Grécia. Não seria isso uma forma de conhecimento?

Não se deve confundir Aristóteles com o racionalismo abstrato, cartesiano, do neoclassicismo francês, ou mesmo do positivismo e naturalismo. Mas também não é possível uma leitura platônica da Poética, tal como fizeram os românticos. A estética romântica, com sua palavra de ordem da arte como expressão do sentimento e com a teoria do gênio, retoma a noção de poesia como furor, como inspiração. Desta visão resulta a noção da catarse como momento supremo de explosão do sentimento. O universal fantástico, a autonomia e a positividade da arte dos românticos é, não obstante, uma conquista em relação ao platonismo antigo. Platão desdenhava a arte; os românticos valorizaram-na. Com estes, o raptus estético, a intuição, transformou-se em valor último, na unidade e universalidade puras e absolutas.

A catarse de Aristóteles é uma clarificação racional e intelectual e comporta uma espécie de sublimação trágica, por intermédio de uma razão discursiva e objetiva. Ela deve contemplar a passagem do informal para o formal e consiste na purificação dos excessos no sentimento de piedade e terror, pela razão, reconduzindo-os em direção à virtude. A verdade e a moralidade são as finalidades últimas da arte e não os sentimentos e as imagens. A catarse na poesia trágica, assim, por obra da ação 
serena da razão provoca um direcionamento rumo à virtude, base de toda a ética, elemento primordial para o tomar decisões que envolvem a pólis. Mas, como se configura essa universalidade-racionalidade? Aristóteles aborda essa questão ao tratar da poesia (como universal) em comparação à história (como particular).

Lê-se na Poética (IX, 1451 a 36 - 1451 b 10) que o poeta não descreve coisas realmente acontecidas, mas aquilo que pode vir a acontecer, segundo as leis da verossimilhança ou necessidade. Ele não difere do historiador porque um escreve em versos e o outro em prosa. O historiador descreve fatos realmente acontecidos e o poeta fatos que poderiam ter acontecido. A poesia, portanto, segundo Aristóteles, é mais filosófica e mais elevada que a história: ela representa o universal e a história o particular. "Por 'referir-se ao universal' entendo eu atribuir a um indivíduo de determinada natureza pensamentos e ações que, por liame de necessidade e verossimilhança, convêm a tal natureza; e ao universal, assim entendido, visa a poesia, ainda que dê nomes às suas personagens..." (Poética, IX 1451 b 5-10).

Vamos, enfim, a Brecht, em especial quando o autor trata do teatro como diversão e das relações deste com a ciência. No Pequeno organon lê-se: "E a catarse aristotélica, a purificação pelo terror e pela piedade, ou a purificação do terror e da piedade, não é uma ablução realizada simplesmente de uma forma recreativa, é, sim, uma ablução que tem por objetivo o prazer" (Brecht, 1978, p.102). Mais adiante, "A ciência e a arte têm de comum o fato de ambas existirem para simplificar a vida do homem; a primeira ocupada com a sua subsistência, a segunda, em proporcionar-lhe diversão" (p.107).

Brecht aproxima-se de Aristóteles ao dar à arte um valor de conhecimento, ao vinculá-la à política. Contudo, ambos se distanciam quanto ao atributo específico da política. Para Brecht, a revolução proletária está no horizonte. A catarse aristotélica expurga os sentimentos, o terror e a piedade, com vistas à virtude da ética e da política.

Brecht contrapõe-se ao aristotelismo, tal como lido e praticado pelo naturalismo positivista do final do XIX e início do XX. O naturalismo psicológico foi o provocador da identificação entre personagem e público, querendo, com isso, selar o seu valor ideológico, com vistas à hegemonia 
burguesa. O horizonte dessa aproximação, portanto, vincula-se ao ideário do individualismo, do indivíduo psicologicamente cindido, para despertar, por empatia, a identificação do conflito burguês como sendo universal. Mas isso não é Aristóteles. Portanto, não procede a contraposição de Brecht a Aristóteles, tendo como base o teatro naturalista ou expressionista do início do século XX, como se estes fossem a expressão depurada da Poética. O naturalismo positivista e psicológico procurou na Poética elementos que reforçavam os seus pressupostos, chegando a descaracterizar a noção de práxis, tomando-a com uma ação qualquer, ou mesmo lendo a mimese como imitação de uma "fatia de vida".

Brecht (1978, p.82) contrapõe-se à identificação do público com os heróis. Em suas palavras: "Numa representação em que não se pretenda uma metamorfose integral, podem utilizar-se três espécies de recursos para distanciar a expressão e a ação da personagem apresentada: 1. recorrência à terceira pessoa; 2 . recorrência ao passado; 3 . intromissão de indicações sobre a encenação e de comentários".

Qualquer leitor, em sã consciência, pode reconhecer qualquer um desses recursos nas tragédias gregas, como, aliás, Anatol Rosenfeld já detectou em seu texto $O$ teatro épico. Esses recursos - além de outros, como a música ou o cartaz - procuram evitar a identificação do espectador com a personagem. Porém, no subsolo da idéia, ou melhor, da intenção de identificação está o pressuposto positivista do homem/espectador como uma tábula rasa, como se ele fosse ao teatro desprovido de si, de seu senso crítico, de sua racionalidade, de seus desejos, de sua imaginação, de suas ideologias etc. Esse precisamente é o objetivo de Brecht: desmascarar a pseudo-isenção do público e, com isso, acirrar as fissuras ideológicas do individualismo burguês.

$\mathrm{Na}$ outra ponta, o conceito de catarse sob a conotação românticoidealista, de inspiração nitidamente platônica, terminou prevalecendo na polaridade distanciamento/identificação. Brecht e Aristóteles prevêem, como vimos, uma finalidade explícita ao teatro. A catarse não é instrumento de identificação, mas sim de ablução, de superação. Em última instância, no interior dos propósitos éticos de Aristóteles os heróis míticos e suas culpas não devem ser modelos a seguir. Enquanto lição pedagógica, o importante na tragédia é o impulso heróico de superação da culpa, para evidenciar a virtude, esta sim heroína suprema.

Em Brecht, a finalidade é diversa. O aparente ato individual, em uma encenação brechtiana, deve ser enfatizado como gesto social, demarcador de fronteiras de classes, que, enquanto gesto, ao procurar esconder, denuncia sua filiação classista, revela e escamoteia os seus pro- 
pósitos ideológicos. É neste jogo duplo e contraditório dos atos individuais, às vezes heróicos, que o teatro de Brecht incide, para enfatizar, sempre, a opressão, a dominação e a luta de classes.

Por fim, a tragédia grega, objetivo de análise de Aristóteles em sua Poética, não pode ser confundida com aquilo que Brecht denominou Forma Dramática de Teatro, contrariamente à Forma Épica. A emoção não está ausente no teatro épico. Assim como a razão participa da tragédia. A polaridade proposta por Brecht refere-se muito mais às cenas naturalista e expressionista, que não são, de forma alguma, expressões últimas e acabadas, demonstrações perfeitas da Poética aristotélica.

O filósofo italiano, Galvano Della Volpe, em Esboço de uma história do gosto (1983, p.103) sintetiza a relação de Brecht e Aristóteles nos seguintes termos:

Estamos de acordo com Aristóteles - prossegue Brecht - quando se trata de defender que o coração da tragédia é a fábula [contra a sobrevalorização romântica dos caracteres e das personagens-heróis], mesmo se não estamos de acordo quanto aos objetivos pelos quais deve ser apresentada (1955) [Pequeno organon]. O que significa, não tanto (como alguns pensaram) uma oposição à genuína catarse aristotélica, mas antes (pelo menos assim o julgamos) uma refutação da persistente interpretação romântica e idealista, que faz da catarse um meio para atingir estados de sonho e contemplação etc. De resto, a formação de hábitos racionais, e morais que resultam da catarse trágica, segundo Aristóteles, parece-nos ser um claro precedente clássico desta moderníssima poética dramática, racionalista e realista, que chega ao ponto de apresentar a instância de que talvez seja necessário que os fatos apresentados pelo ator épico já sejam conhecidos (e nesse caso, os fatos históricos seriam os mais adequados).

BOLOGNESI, M. F. Brecht and Aristotle. Trans/Form/Ação (São Paulo), v.25, p.67-78, 2002.

- ABSTRACT: The Bertold Brecht's conception of the theater is not radically opposed to that of Aristotle. Brechtian aesthetics is, in many aspects, heiress of Aristotle's ideas. The epic theater proposed by Brecht opposes naturalistic theater and psychological drama. Mimesis and catharsis don't mean the identification of the public with the scene and the hero.

- KEYWORDS: Epic theater; dramatic theater; Aristotle; Brecht. 


\section{Referências bibliográficas}

ARISTÓTELES. Poética. Tradução, comentários e índices analítico e onomástico de Eudoro de Souza. Ética a Nicômaco. São Paulo: Abril Cultural, 1979. (Os pensadores).

BAYER, R. Historia de la estetica. México: FCE, 1965.

BESNIER, A distinção entre práxis e poiésis em Aristóteles. Analytica (Rio de Janeiro), v.1, n.3, p.127-63, 1996.

ROSENFELD, A. O teatro épico. São Paulo: Ao Livro Técnico, 1965.

BOSI, A. Reflexões sobre a arte. São Paulo: Ática, 1985.

BRECHT, B. Estudos sobre teatro. Rio de Janeiro: Nova Fronteira, 1978.

BRUN, J. Aristote et le lycée. Paris: PUF, 1970.

CARLSON, M. Teorias do teatro. Estudo histórico-crítico, dos gregos à atualidade. São Paulo: Editora UNESP, 1997.

DELLA VOLPE, G. Opere. A cura di Ignazio Ambrogio. Roma: Riuniti, 19721973. 6v.

. Esboço de uma história do gosto. Lisboa: Estampa, 1983.

GIVONE, S. Storia dell'estetica. Roma: Laterza, 1990

GOLDSCHMIDT, V. Les dialogues de Platon. Paris: PUF, 1947.

"Le probléme de la tragédie d'apres Platon". In: Questions platoniciennes. Paris: J. Vrin, 1970.

JAEGER, W. Aristóteles. México: FCE, 1946.

Paideia. Lisboa: Aster, s. d.

KNOLL, V. Sobre a questão da mimesis. Discurso, n.27, p.61-81. São Paulo: FFLCH-USP, 1996. Revista do Departamento de Filosofia da USP.

MOREAU, J. Aristote et son école. Paris: PUF, 1962.

PEREIRA, W. J. Della Volpe crítico de Lukács. Trans/Form/Ação (São Paulo), v.5, p.55-62, 1982.

SCHUHL, P-M. Études platoniciennes. Paris: PUF, 1960.

. Platon et l'art de son temps (Arts plastiques). Paris: PUF, 1952.

SPINA, S. Introdução à poética clássica. São Paulo: FTD, 1967.

VENTURI, L. Storia della critica d'arte. Torino: Einaudi, 1964.

VERNANT, J-P., VIDAL-NAQUET, P. Mito e tragédia na Grécia antiga. São Paulo: Duas Cidades, 1977. 